\title{
Urinary hormone levels during the natural menstrual cycle: the effect of age
}

\author{
V Hall Moran, H L Leathard and J Coley ${ }^{\mathbf{1}}$ \\ Department of Nursing Studies, St Martin's College, Lancaster LA1 3JD, UK \\ ${ }^{1}$ Unilever Research Colworth, Colworth House, Sharnbrook, Bedfordshire MK44 ILQ, UK \\ (Requests for offprints should be addressed to V Hall Moran, Department of Midwifery Studies, University of Central Lancashire, Preston PR1 2HE, UK; \\ Email: vlmoran@uclan.ac.uk)
}

\begin{abstract}
A number of studies have identified hormonal changes in women during their reproductive lifespan, many focusing upon changes in women over the age of 40 years. The present study has determined the effect of increasing age on hormone levels over three decades.

Daily early morning urine samples were assayed for estrone-3-glucuronide (E3 G), pregnanediol-3glucuronide (P3 G), testosterone-17-glucuronide (T17 G), FSH and LH. An examination of the validity of using creatinine as a volume adjuster in urine samples formed an integral part of the analysis. Volunteers were healthy women who had regular (25-35 days) cycles, were not taking oral contraceptives, hormone therapies or any other medication. Three age groups were compared: 20-29 years $(n=13), 30-39$ years $(n=9)$ and $40-49$ years $(n=13)$. Statistical analyses were carried out using twoway ANOVA and post hoc $t$-tests.

Creatinine excretion, despite revealing no cycle-related variation in any age group, showed a decline with increasing age. Creatinine output was significantly lower in the $40-49$ years age group in all phases of the cycle than in the 20-29 and 30-39 groups $(P<0 \cdot 0001)$. Uncorrected levels
\end{abstract}

of E3 G were significantly higher in the 30-39 years group when compared with the 40-49 age group $(P<0 \cdot 0001)$. Uncorrected P3 G output was significantly higher in women aged $20-29$ years than in women aged $40-49$ years $(P<0 \cdot 001)$ and levels of uncorrected T17 G were higher in the 20-29 year age group when compared with the 30-39 or 40-49 years age group $(P<0 \cdot 0001)$.

The present study is consistent with previous reports that have revealed a decline in creatinine clearance with increasing age, and therefore casts into some doubt the validity of using creatinine clearance as a procedure to correct for volume fluctuations in differing age groups of women. The study also demonstrates unequivocally that age-related variations in hormone levels are not restricted to women over 40 years of age. The novel finding of highly significant differences in mean levels of T17 G between the age groups is of considerable interest. It is presently unclear whether this resulted from specifically increased ovarian and/or adrenal secretion. The possible impacts of changes in testosterone levels during the female reproductive lifespan merits further study.

Journal of Endocrinology (2001) 170, 157-164

\section{Introduction}

Age-related changes in female sex hormones have repercussions upon fertility and fecundity, which are generally accepted to decline with advancing age. Previous studies of hormonal change during women's reproductive life have produced conflicting and incomplete results. This may be due to methodological limitations arising from small sample sizes, inclusion of anovulatory cycles and/or infrequent hormone measures by the various authors (Klein et al. 1996). For example, MacNaughton et al. (1992) took just two blood samples to represent follicular and luteal levels of the female sex hormones during the menstrual cycle.

Furthermore, the use of serum samples to characterise hormonal change may provide a distorted picture. Many ovarian steroid and gonadotrophin secretions are episodic and pulsatile in nature (Huff \& Pauerstein 1979). The frequent and wide fluctuation of serum hormone levels over $24 \mathrm{~h}$ therefore render the interpretation problematic where single or few serum determinations are used. It has been noted that the cyclic nature of female reproduction can only be fully described by continuous frequent measurements, and for these reasons the use of daily urine specimens to study the relationship between hormones and health has been recommended by Dennerstein et al. (1993). Urine analysis minimises the impact on measured values of the diurnal and pulsatile fluctuations reported to occur in blood specimens, avoids the stressful effects of daily venepuncture, and samples are more easily collected on a daily basis. Furthermore, unlike plasma samples, urine samples may be collected by unsupervised participants, 
thus facilitating studies of ovarian function with daily monitoring over extended time periods.

Few studies have examined age-related variations in urinary sex hormones, and those that have are also limited by methodological weaknesses, such as infrequent weekly urine sampling (Metcalf \& Livesey 1985) and normalisation of hormone excretion to levels of creatinine (Metcalf \& Livesey 1985, Santoro et al. 1996). Adjustment of urinary hormone concentrations using creatinine measurement has been discouraged by Zacur et al. (1997) who described a decline in mean baseline urinary creatinine clearance with increasing age, independent of race and weight.

Few studies have investigated the possibility of agerelated variation in testosterone levels. Zumoff et al. (1995) reported that the 24-h mean plasma concentration of testosterone levels in 33 women revealed a steep decline with age, such that data from women in their forties revealed testosterone levels less that half of those of women in their early twenties. To our knowledge, however, levels of urinary testosterone metabolites have not previously been compared across age groups.

The present study, which was part of a larger investigation of menstrual cycle-related physiological and psychological variations (Hall 1998), describes the effect of increasing age in women with regular menstrual cycles on urine levels of follicle-stimulating hormone (FSH), luteinising hormone (LH), estrone-3-glucuronide (E3 G), pregnanediol-3-glucuronide (P3 G) and testosterone-17glucuronide $(\mathrm{T} 17 \mathrm{G})$. Particular attention is paid to age- and cycle-related variations in creatinine levels and the potential impact of correcting hormone levels for creatinine clearance on the interpretation of the data.

\section{Materials and Methods}

\section{Participants}

Thirty-five healthy, naturally cycling women with regular menstrual cycles (25-35 days) volunteered for the study. Women were excluded from the study if they: were pregnant or breast-feeding during the last 12 months; had undergone a hysterectomy; used oral contraceptives in the preceding 6 months; used any medication known or suspected to alter mood or endocrine functioning; were on a strict diet or strenuous exercise regimen; had sought medical help for premenstrual or menopausal symptoms; or were experiencing any very stressful life experiences at the time. All women were paid $f_{1} 10$ upon completion of the study. The cycle data were divided into 10-year age groups as follows: $20-29$ years $(n=13) ; 30-39$ years $(n=9)$; and $40-49$ years $(n=13)$. The study was compliant with the College's ethical principles and guidelines for research involving human subjects. Informed consent was obtained from each participant following full explanation of the purpose and nature of the study.
Assays

Urine samples Daily early morning urine (EMU) samples were collected for a period of 5 weeks. All subjects participating in the study were provided with instructions for collection and cool storage of urine, together with a plastic box containing forty $30 \mathrm{ml}$ plastic tubes containing dried azide as a preservative and separate labels. Samples were brought into the research room at the end of the study, aliquotted into $5 \mathrm{ml}$ tubes and stored at $4{ }^{\circ} \mathrm{C}$ until assayed. Any missing samples were noted and substituted with vials containing buffer solution.

Hormone assays Urinary levels of LH, FSH, E3 G, P3 G and T17 G were determined by ELISA. Antibodies were immobilised on nylon pegs, the dimensions of which were matched to the dimensions of the wells in a standard 96-well flat-bottomed microtitre plate (Savage et al. 1993, Davis et al. 1994). Solutions were dispensed using a Biomek 1000 Robotics Workstation (Beckman Instruments), programmed to dispense a range of volumes between 20 and $200 \mu$ l. Steroid analytes were measured in competitive assays whereas the peptide hormones were measured in paired monoclonal antibody sandwich assays. Each assay plate consisted of ten standards (in duplicate), three quality control (QC) samples (high, medium and low, in triplicate) and up to 30 samples (in duplicate). Tween 20 was added to all urine samples $(0 \cdot 1 \% \mathrm{v} / \mathrm{v})$ to reduce surface tension and thereby achieve greater pipetting accuracy. Intraassay and interassay coefficients of variation were on average less than $8 \%$ for the three QC samples in each of the five assays (range 3.8\%-10.9\%). Each assay was highly specific for the steroid it measured, with very low cross-reactivity to other natural steroids (Hall 1998).

E3 $\mathrm{G}$ and P3 G assays E3 G and P3 G monoclonal antibodies were immobilised on anti-mouse $\operatorname{IgG}$ coated nylon pegs by incubation of the pegs in either E3 G or P3 $\mathrm{G}$ antibody solutions for $1 \mathrm{~h}$ at room temperature. The pegs were rinsed in $0.01 \mathrm{M}$ phosphate-buffered saline, $\mathrm{pH} 7 \cdot 3$ containing $0 \cdot 1 \%$ Tween 20 and $0 \cdot 01 \%$ sodium azide (PBSTA) and then placed in wells of a microtitre plate pre-dispensed with either steroid standard solution or urine sample and alkaline phosphatase labelled E3 G or P3 G. After $1 \mathrm{~h}$ at room temperature the pegs were removed, rinsed in PBSTA and placed in fresh wells pre-dispensed with $p$-nitrophenyl phosphate $\left(1 \mathrm{mg} \mathrm{ml}^{-1}\right)$ in $1 \mathrm{M}$ diethanolamine at $\mathrm{pH} 9 \cdot 8$ to develop colour. The pegs were removed after $45 \mathrm{~min}$ incubation at room temperature and the solution optical densities (ODs) read at $405 \mathrm{~nm}$.

T17 G assay T17 G standard solution or urine sample, alkaline phosphatase labelled T17 G and monoclonal T17 $\mathrm{G}$ antibody were added to the wells of a microtitre plate. After $30 \mathrm{~min}$, anti-mouse IgG coated pegs were 
Table 1 Criteria for cycle phase determination using hormone events and menstruation as markers

\begin{tabular}{|c|c|c|}
\hline \multirow[b]{2}{*}{ Phase } & Hormone changes & Days assigned to phase \\
\hline & & \\
\hline Bleeding phase & $\begin{array}{l}\text { Low levels of oestrogen, } \\
\text { progesterone, FSH, LH and } \\
\text { testosterone }\end{array}$ & $\begin{array}{l}\text { Day }-1 \text { before bleeding through } \\
\text { to }+4 \text { of bleeding }\end{array}$ \\
\hline Follicular phase & $\begin{array}{l}\text { Rising levels of oestrogen, low } \\
\text { levels of progesterone }\end{array}$ & $\begin{array}{l}\text { Day }+5 \text { from the start of bleeding } \\
\text { through to }-4 \text { before } \mathrm{LH}_{\max }\end{array}$ \\
\hline Ovulatory phase & $\begin{array}{l}\text { Peak of oestrogen, followed by } \\
\text { LH/FSH peak }\end{array}$ & Day -3 through to +2 of $\mathrm{LH}_{\max }$ \\
\hline Luteal phase & $\begin{array}{l}\text { Oestrogen levels fall, } \\
\text { progesterone levels rise to } \\
\text { sustained peak }\end{array}$ & $\begin{array}{l}\text { Day }+4 \text { after } \mathrm{LH}_{\max } \text { through to } \\
-2 \text { before the start of bleeding }\end{array}$ \\
\hline
\end{tabular}

placed in the wells. After a further $1 \mathrm{~h}$ at room temperature the pegs were rinsed in PBSTA and the colour developed and ODs read as described above.

LH and FSH assays Nylon pegs were sensitised with monoclonal antibodies recognising either the $\beta$-subunit of FSH or the $\alpha$-subunit of $\mathrm{LH}$ as previously described (Davis et al. 1994). The pegs were placed in microtitre wells containing either urine samples or standard antigen solution. After $1 \mathrm{~h}$ at room temperature the pegs were removed and placed in fresh wells containing alkaline phosphatase conjugated to monoclonal antibodies recognising either the $\alpha$-subunit of FSH or the $\beta$-subunit of $\mathrm{LH}$. After a further $1 \mathrm{~h}$ at room temperature the pegs were rinsed in PBSTA and the colour developed and ODs read as described above.

Creatinine Creatinine levels were measured using a kinetic Jaffe method on the Hitachi 704EC Automatic Analyser (Boehringer Mannheim UK Ltd, Lewes, East Sussex, UK) using a standard Boehringer test kit.

\section{Determination of cycle phase}

Menstrual bleeding records and hormone measures were both used to characterise the cycle phases of the women in the present study. LH levels were used to identify time of ovulation. For a woman's cycle to be classified as ovulatory: (a) her basal body temperature data had to give indication of ovulation (i.e. a biphasic profile); (b) there had to be a preovulatory rise in E3 G; (c) a definite LH peak had to follow this; (d) her cycle had to exhibit a sustained elevated P3 G level in the second half; and (e) a fall in progesterone from peak luteal phase levels at least 1 day prior to the onset of menstruation had to be perceivable. Only the participants whose data fulfilled these criteria were included in the present study.

The menstrual cycle of each individual was divided into four phases (bleeding, follicular, ovulatory and luteal) which were intended to represent four distinct hormonal conditions (see Table 1). Cycle phase was assigned both by counting backwards and forwards from the onset of menstruation, and by centring the data around $\mathrm{LH}_{\max }$ (the point where the LH excretion peaked). The bleeding phase included the day before the onset of menses because hormone levels were already at low 'bleeding phase' levels and thus could be classified as belonging to the same hormonal phase. The third day after $\mathrm{LH}_{\max }$ was omitted from analysis in all cycles due to it being a 'transitional' day where LH and FSH levels had dropped and P3 G levels, although starting to rise, remained relatively low. Data for additional selected days were omitted from cycles with follicular and/or luteal phases longer than 10 days.

\section{Statistical analyses}

A two-way ANOVA, with age as a between-subjects factor and phase as a within-subjects factor, was used to test differences between the two groups and between cycle phase. Differences were regarded as statistically significant at $P<0 \cdot 01$. Differences between age groups were then examined for each cycle phase using Student's $t$-tests. In order to allow for multiple comparisons, a conservative significance level of $P<0 \cdot 005$ was applied. Analyses were carried out using Statistical Analysis System (SAS) by Unilever's Statistical Department.

\section{Results}

\section{Volunteer characteristics}

There were significantly more single, $(n=11, P<0 \cdot 0001)$ nulliparous $(n=13, P<0 \cdot 0001)$ women in the $20-29$ years age group than in the $30-39$ (single $=3$; nulliparous $=3$ ) and $40-49$ years age groups (single $=0$; nulliparous $=5$ ). The groups did not significantly differ with respect to ethnic origin, alcohol consumption, smoking status, 
Table 2 ANOVA analyses on comparisons between women aged 20-29, 30-39 and 40-49 years

\begin{tabular}{|c|c|c|c|c|c|c|}
\hline & \multicolumn{3}{|c|}{ Uncorrected values } & \multicolumn{3}{|c|}{ Corrected values } \\
\hline & d.f. ${ }_{\text {phase }}$ d.f.f.error & $F$ ratio & $P$ & d.f. $_{\text {group }}$ d.f.f.error & $F$ ratio & $P$ \\
\hline \multicolumn{7}{|c|}{ Hormone } \\
\hline $\mathrm{FSH}$ & 2,90 & $1 \cdot 53$ & NS & 2,90 & $12 \cdot 06$ & $<0.0001$ \\
\hline LH & 2,90 & 0.98 & NS & 2,90 & 0.92 & NS \\
\hline E3G & 2,90 & $10 \cdot 80$ & $<0.0001$ & 2,90 & $1 \cdot 21$ & NS \\
\hline P3G & 2,90 & 7.09 & $<0.001$ & 2,90 & $4 \cdot 07$ & NS \\
\hline $\mathrm{T} 17 \mathrm{G}$ & 2,90 & $30 \cdot 32$ & $<0.0001$ & 2,90 & 18.55 & $<0.0001$ \\
\hline
\end{tabular}
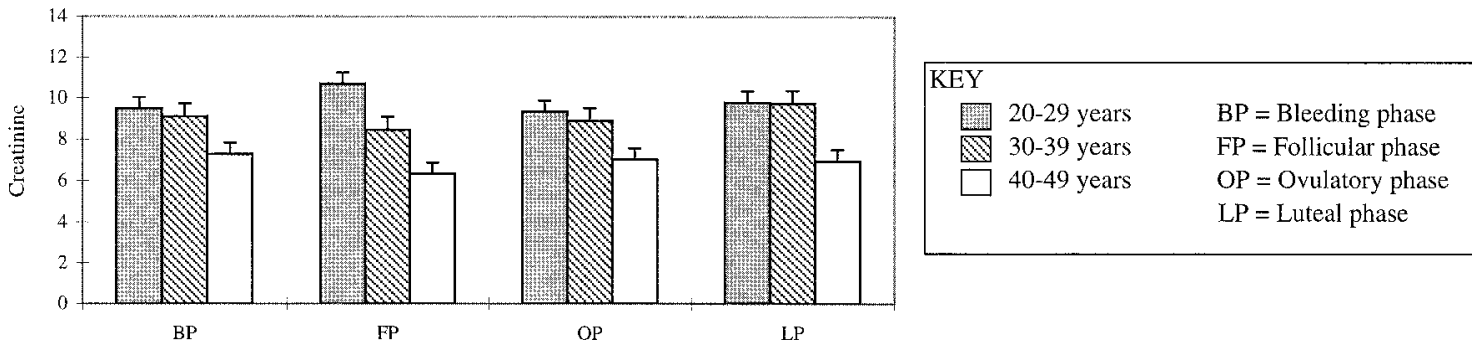

Figure 1 Mean ( \pm S.E.M.) creatinine concentrations across four phases of the menstrual cycle in three age groups of women.

existence of premenstrual symptoms, or in their perception of their own health. No significant differences in mean cycle lengths or duration of menses were found between the three age groups, although cycle length tended to be shorter in women aged 40-49 (mean cycle length of $27 \cdot 6$ days) than those aged $20-29$ (29.8 days) and 30-39 (29.7 days) years.

Urinary hormone values in four hormonally defined phases of the menstrual cycle of women aged 20-29, 30-39 and 40-49 years

The following hormone concentrations are given as values for both uncorrected and corrected for creatinine clearance. Age-related differences in the levels of creatinine corrected (identifiable by the suffix $\mathrm{Cr}$ ) and uncorrected hormone values between the three age groups are discussed in the following text. Table 2 presents a comparison of the three age groups by ANOVA.

Creatinine As shown in Fig. 1, creatinine concentration in the urine showed a decline with increasing age. Creatinine concentration was significantly lower in the 40-49 age group in all phases of the cycle than the 20-29 and $30-39$ groups $(F(9,90)=30 \cdot 34, P<0 \cdot 0001)$. No cyclerelated variation in creatinine was present in any age group.

FSH Uncorrected hormone values revealed no significant variation in FSH between the age groups (Fig. 2a).

Follicular phase FSH (Cr), however, was significantly higher in women aged $40-49$ years $(1.96 \pm 0.18 \mathrm{mIU} / \mathrm{mg}$
Cr) than in women aged 30-39 years $(1 \cdot 14 \pm 0 \cdot 21$ $\mathrm{mIU} / \mathrm{mg} \mathrm{Cr}, P<0 \cdot 005)$ (Fig. 2a).

LH Neither LH (Cr) nor uncorrected LH concentrations revealed any significant differences between the three age groups (Fig. 2b).

E3 G Uncorrected levels of E3 G were significantly higher in the ovulatory phase in the 30-39 years group $(42.55 \pm 2.64 \mathrm{ng} / \mathrm{ml})$ when compared with the 40-49 $(27 \cdot 96 \pm 2 \cdot 29 \mathrm{ng} / \mathrm{ml}, \quad P<0 \cdot 0001)$ age group (Fig. 3a). There were no differences between the groups in bleeding, follicular or luteal phase levels of E3 G $(\mathrm{Cr})$.

Mean E3 G (Cr) levels did not differ significantly between the age groups in any phase of the cycle.

P3 G As illustrated in Fig. 3b, there appears to be a tendency for P3 G output in each phase of the cycle to decrease with age. These differences were not significant, however, except in the luteal phase where levels of P3 G were higher in women aged 20-29 years $(23280 \pm 1874 \mathrm{ng} / \mathrm{ml})$ than in the $40-49$ age group $(15530 \pm 1874 \mathrm{ng} / \mathrm{ml}, P<0 \cdot 005)$.

Levels of P3 G (Cr) also appeared to be higher in the youngest age group throughout the cycle (Fig. 3b) but the differences were not significant.

T17 G Output of T17 G was higher in each phase of the cycle in the 20-29 age group when compared with the 30-39 or 40-49 years age group (Fig. 3c). The values for the youngest age group ranged from $211.5 \mathrm{ng} / \mathrm{ml}$ in the bleeding phase to $304.5 \mathrm{ng} / \mathrm{ml}$ in the luteal phase, while 


\section{Uncorrected values}

$2 a$

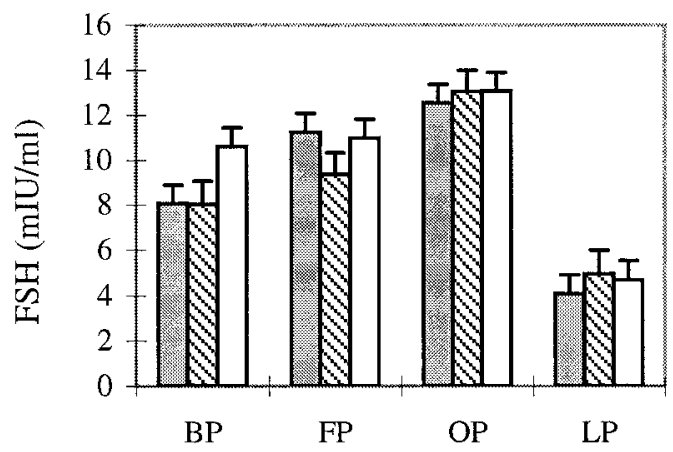

$2 b$

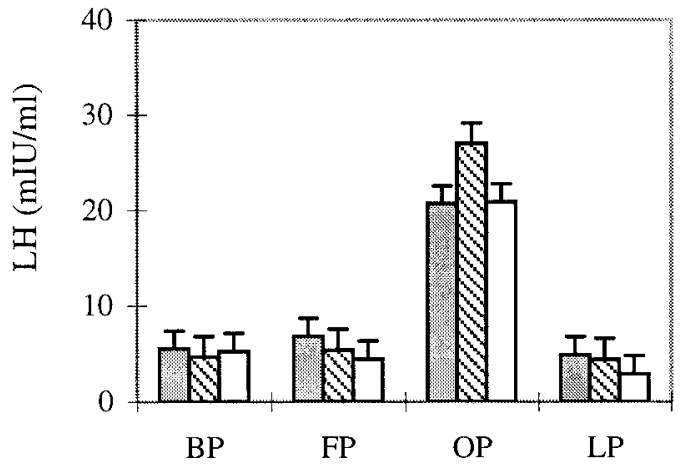

\section{Corrected values}
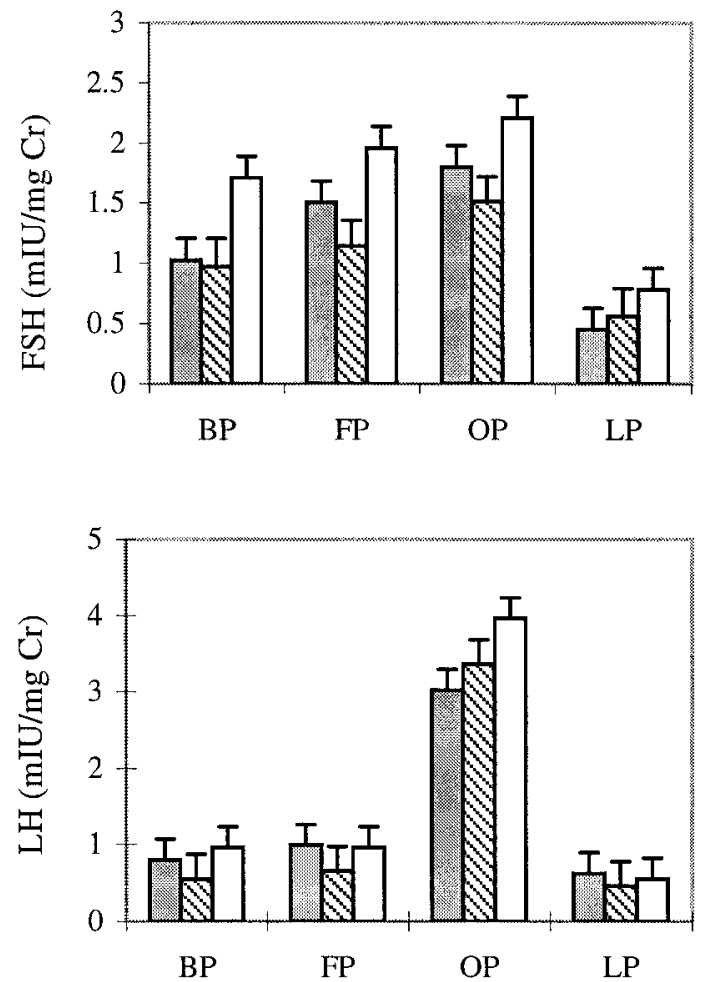

Figure 2 Mean ( \pm S.E.M.) gonadotrophic hormone concentrations in three age groups of women. Uncorrected and creatinine corrected $(\mathrm{Cr})$ values are given. See Fig. 1 for key.

equivalent values for women aged $30-39$ years and 40-49 years were $128 \cdot 3-248 \cdot 6 \mathrm{ng} / \mathrm{ml}$ and $161 \cdot 9-249 \cdot 2 \mathrm{ng} / \mathrm{ml}$ respectively. Bleeding phase levels of T17 G were significantly higher in women aged 20-29 years $(211.5 \pm 17 \cdot 7 \mathrm{ng} / \mathrm{ml})$ compared with those aged 30-39 years $(128.3 \pm 20 \cdot 4 \mathrm{ng} / \mathrm{ml}, \quad P<0 \cdot 005)$. Similarly, mean T17 G concentrations in the follicular phase were significantly higher in the 20-29 years age group $(228.6 \pm 17 \cdot 7 \mathrm{ng} / \mathrm{ml})$ than either the 30-39 years $(113.0 \pm 20 \cdot 4 \mathrm{ng} / \mathrm{ml}, \quad P<0 \cdot 0001)$ or the $40-49$ years $(131.4 \pm 17 \cdot 7 \mathrm{ng} / \mathrm{ml}, P<0 \cdot 0005)$ age groups. Ovulatory phase levels of T17 G too were significantly greater in younger women $(280 \cdot 2 \pm 17 \cdot 7 \mathrm{ng} / \mathrm{ml})$ than women aged 30-39 years $(149 \cdot 5 \pm 20 \cdot 4 \mathrm{ng} / \mathrm{ml}, P<0 \cdot 0001)$ or $40-49$ years $(179 \cdot 0 \pm 17 \cdot 7 \mathrm{ng} / \mathrm{ml}, \quad P<0 \cdot 0001)$. No significant differences between age groups were observed in luteal phase levels of T17 G.

In contrast to the uncorrected values, overall $\mathrm{T} 17 \mathrm{G}$ (Cr) levels were lower in the 30-39 years age group throughout the cycle (range, $12 \cdot 68-26 \cdot 04 \mathrm{ng} / \mathrm{mg} \mathrm{Cr}$ ) than in women aged 20-29 (range, 26.06-44.02 ng/mg Cr) or 40-49 (range, $24 \cdot 18-39 \cdot 36 \mathrm{ng} / \mathrm{mg} \mathrm{Cr}$ ) years. Levels of
T17 G (Cr) in women aged 30-39 years ranged from $12.68 \mathrm{ng} / \mathrm{mg} \mathrm{Cr}$ in the follicular phase to $26.04 \mathrm{ng} / \mathrm{mg} \mathrm{Cr}$ in the luteal phase, while equivalent values for women aged $20-29$ years and $40-49$ years were $26 \cdot 06-41 \cdot 20 \mathrm{ng} /$ $\mathrm{mg} \mathrm{Cr}$ and $24 \cdot 18-39 \cdot 36 \mathrm{ng} / \mathrm{mg} \mathrm{Cr}$ respectively. Mean T17 G (Cr) levels were low in the ovulatory phase of women aged 30-39 years $(16 \cdot 30 \pm 4 \cdot 77 \mathrm{ng} / \mathrm{mg} \mathrm{Cr})$ compared with women aged 20-29 years $(44 \cdot 02 \pm 4 \cdot 13 \mathrm{ng} /$ $\mathrm{mg}$ Cr, $P<0 \cdot 0001)$, and mean luteal phase T17 G $(\mathrm{Cr})$ was low in 30-39-year-olds $(26 \cdot 04 \pm 4 \cdot 77)$ compared with younger age groups $(41 \cdot 15 \pm 4 \cdot 13 \mathrm{ng} / \mathrm{mg} \mathrm{Cr}, P<0 \cdot 005)$. No significant differences between age groups were observed in bleeding and follicular phases.

\section{Discussion}

The present study elucidated age-related variation in both creatinine-corrected and uncorrected urinary steroid and gonadotrophic hormone levels measured using in-house validated ELISA techniques. Strict participant exclusion criteria ensured that the sample consisted of healthy, 


\section{Uncorrected values}

3a

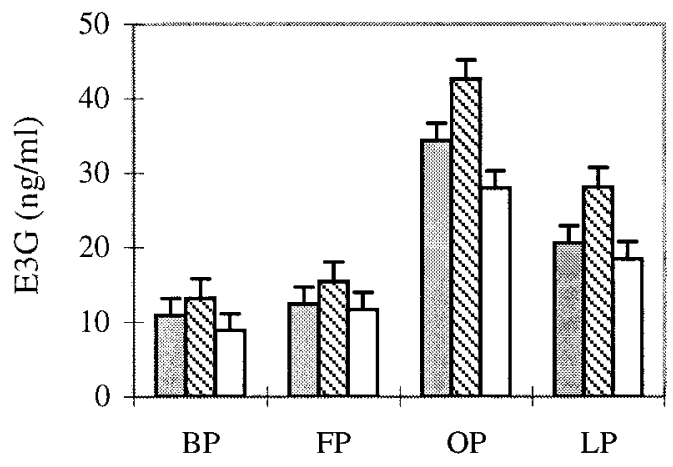

$3 b$

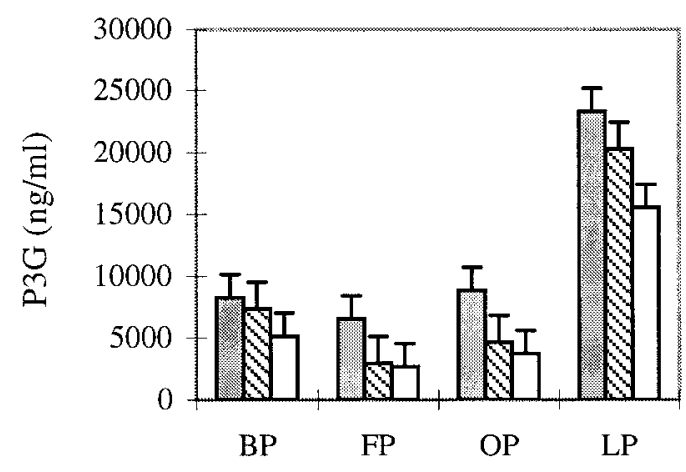

$3 c$

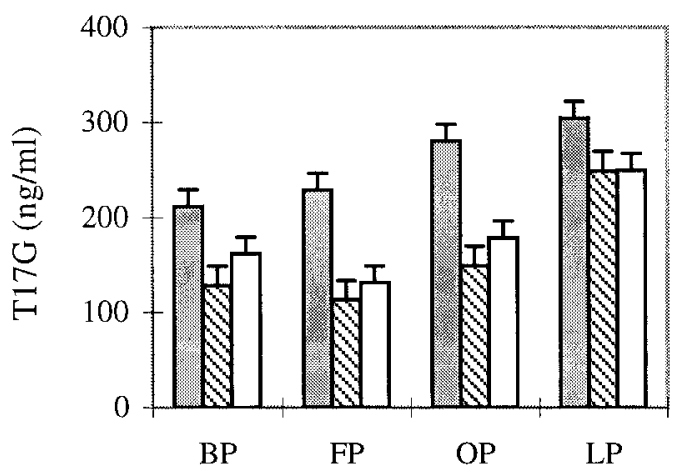

Corrected values
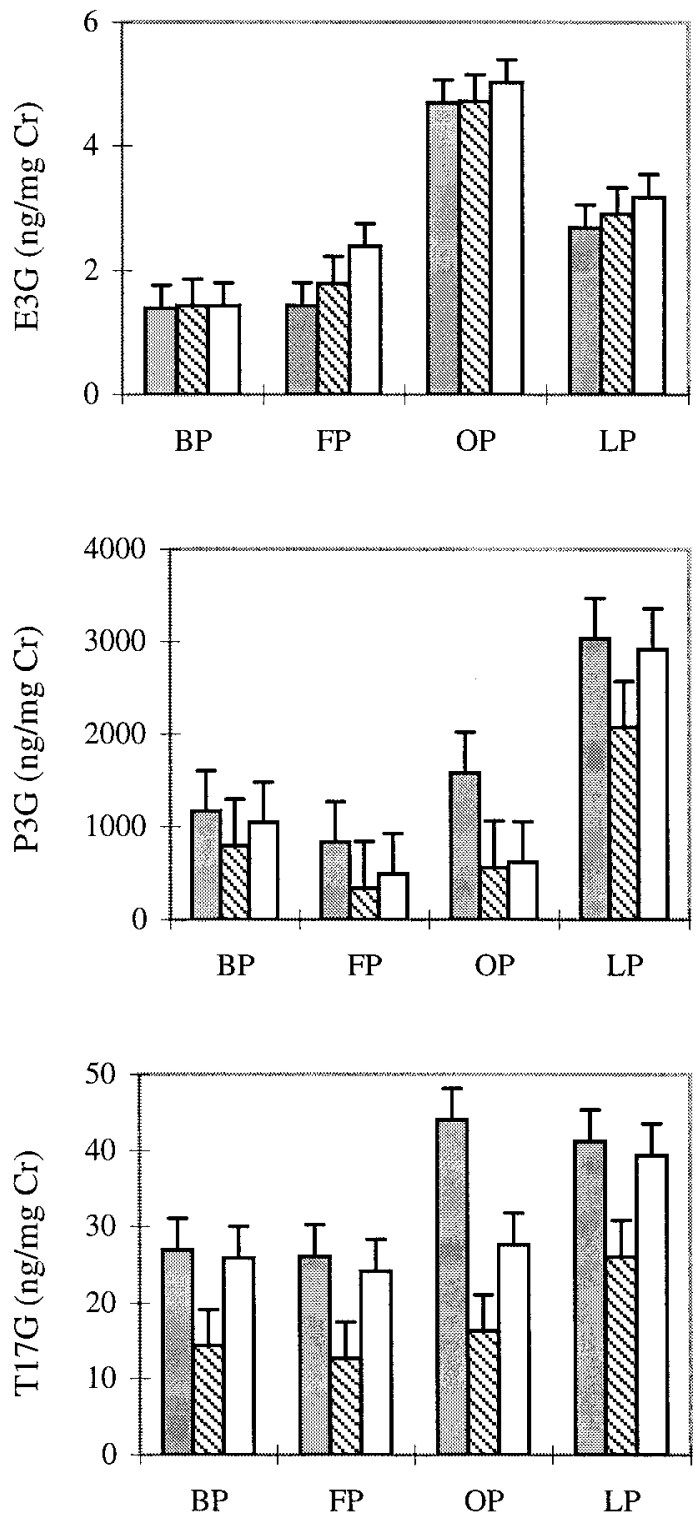

Figure 3 Mean ( \pm S.E.M.) steroid hormone concentrations in three age groups of women. Uncorrected and creatinine corrected $(\mathrm{Cr})$ values are given. See Fig. 1 for key.

regularly cycling women. Cycle phase was determined by scrutinising an individual's hormone data thereby enabling accurate definition of distinct hormonal phases. The fact that most volunteers produced full sets of urine samples endorses the selection of this method from the compliance perspective, and the clear hormone profiles vindicate the reliability of this method for detecting cycle phases.
The present study is consistent with previous reports that have revealed a decline in creatinine clearance with increasing age (Sokoll et al. 1994, Zacur et al. 1997). It has also been found that improved correlations exist between urinary and serum steroid hormone levels when urine samples remain unadjusted for creatinine clearance (Hakim et al. 1994, Zacur et al. 1997). Therefore, the 
validity of using creatinine adjustments when comparing urinary hormone levels between subjects of different ages is cast into some doubt.

Within individuals, however, because there are no cycle-related variations in creatinine excretion, the smoothing out of volume-related fluctuations provides 'cleaner' data for comparing levels in different cycle phases. Both sets of data are, therefore, useful, but for different purposes. The remaining discussion of the agerelated variation in hormone levels will, therefore, focus upon unadjusted urinary hormone levels because these are based on inter-individual comparisons of levels.

In the present study, the uncorrected urinary FSH levels were no higher in women aged 40-49 years than in younger age groups. A monotropic rise in FSH (i.e. without an accompanying increase in LH) is frequently reported in women around 40 years (Sherman et al. 1976, Metcalf et al. 1981, Metcalf \& Livesey 1985) even whilst they are menstruating regularly (Lee et al. 1988, Lenton et al. 1988, Ahmed Ebbiary et al. 1994, Batista et al. 1995, Klein et al. 1996, Santoro et al. 1996). A possible explanation for the absence of significantly elevated FSH levels in the 40-49 years age group in the present study is that the mean age of the group was only 43 years and, as a consequence of the exclusion criteria, did not present with perimenopausal symptoms.

The significant reduction in E3 G ovulatory phase output between the 30-39 and 40-49 years age groups is consistent with the documented decline in ovarian functioning at this stage of life, and with declining fertility (Yen 1991).

Serum levels of progesterone are frequently reported to be comparable in both younger and older women (Fitzgerald et al. 1994, Batista 1995, Klein et al. 1996, Reame 1996). The present study, however, revealed that levels of P3 G were significantly higher in women aged 20-29 years than in older women. These age-related changes in $\mathrm{P} 3 \mathrm{G}$ output might also be reflected in premenstrual symptomatology.

The novel finding of highly significant differences in mean levels of T17 G between the age groups is of considerable interest. In view of their common biosynthetic pathway it is unsurprising that progesterone and testosterone patterns are similar, although statistically significant age-related differences were mainly restricted to testosterone. The striking question that must be addressed is whether or not the relatively high output of these hormones seen in this small group of subjects is typical of the 20-29 age group in general. The absence of a similar pattern in the E3 $\mathrm{G}$ data can be taken as an argument against these volunteers being a group of steroid hypersecretors with an elevated level of androstenedione as the origin of $\mathrm{T} 17 \mathrm{G}$ levels in the present study. A significant source of oestrogens is the conversion of androstenedione to oestrone, whereas a smaller source is the conversion of testosterone to oestradiol (Yen 1991). Androstenedione is also readily converted to testosterone, and accounts for $50-60 \%$ of circulating testosterone levels (Yen 1991). Therefore the observation that urinary E3 G levels did not reflect the high testosterone levels in this age group of women indicates that the androstenedione levels were not high. Thus it is possible that the elevated levels of T17 G shown in the present study may have resulted from specifically increased ovarian and/or adrenal secretion. It is of considerable interest, therefore, to consider the possible physiological and psychological implications of relatively high testosterone levels in 20-29-year-old women and the progressive decline in those with age.

In conclusion, this study has revealed a clear pattern of changes in steroidal sex hormone levels within the reproductive age range while gonadotrophin levels did not. This is consistent with a decline in ovarian but not hypothalamic-pituitary functioning with increasing age. The relationship of these changes to reproductive function and menstrual cycle symptomatology merits further study. Briefly, testosterone and progesterone levels throughout the cycle were highest in the third decade of life then declined. Both hormones have been implicated in premenstrual symptomatology although further research is needed. The possible impact of hormone level changes through one or more pregnancies on the subsequent pattern of progesterone and testosterone production remains to be explored as a possible factor in the decline. In contrast, oestrogen production was well maintained into the fifth decade although the ovulatory peak levels were reduced significantly, perhaps as a prelude to reduced fertility and the onset of menopausal symptomatology.

\section{References}

Ahmed Ebbiary NA, Lenton EA \& Cooke ID 1994 Hypothalamicpituitary ageing: progressive increase in $\mathrm{FSH}$ and $\mathrm{LH}$ concentrations throughout the reproductive life in regularly menstruating women. Clinical Endocrinology 41 199-206.

Batista MC, Cartledge TP, Zellmer AW, Merino MJ, Axiotis C, Bremner WJ \& Nieman LK 1995 Effects of ageing on menstrual cycle hormones and endometrial maturation. Fertility and Sterility 64 492-499.

Davis PJ, Laidler LA, Perry PW, Rossington D \& Alcock R 1994 The detection of infectious pancreatic necrosis virus in asymptomatic carrier fish by an integrated cell-culture and ELISA technique. Journal of Fish Diseases 17 99-110.

Dennerstein L, Brown JB, Gotts G, Morse CA, Farley TMM \& Pinol A 1993 Menstrual cycle hormonal profiles of women with and without premenstrual syndrome. Journal of Psychosomatic Obstetrics and Gynaecology 14 259-268.

Fitzgerald CT, Seif MW, Killick SR \& Bennet DA 1994 Age related changes in the female reproductive cycle. British Journal of Obstetrics and Gynaecology 101 229-233.

Hakim RB, Gray RH \& Zacur HA 1994 Is there a need for creatinine adjustment of urinary steroid hormone levels in studies of early fetal loss? Clinica Chimica Acta 230 209-214.

Hall VL 1998 Effects of cycle phase and sex hormone levels upon physiological and psychological functioning in healthy women: an 
exploration and comparison of natural and oral contraceptive regulated cycles. PhD Thesis. Lancaster University.

Huff RW \& Pauerstein CJ 1979 Human Reproduction. Physiology and Pathophysiology. New York: John Wiley \& Sons.

Klein NA, Battaglia DE, Fujimoto VY, Davis GS, Bremner WJ \& Soules MR 1996 Reproductive ageing: accelerated ovarian follicular development associated with a monotropic follicle-stimulating hormone rise in normal older women. Journal of Clinical Endocrinology and Metabolism 81 1038-1045.

Lee SJ, Lenton EA, Sexton L \& Cooke ID 1988 The effect of age on the cyclical patterns of plasma LH, FSH, oestradiol and progesterone in women with regular menstrual cycles. Human Reproduction 3 851-855.

Lenton EA, Gelsthorp CH \& Harper R 1988 Measurement of progesterone in saliva: assessment of the normal fertile range using spontaneous conception cycles. Clinical Endocrinology 28 637-646.

MacNaughton J, Banah M, McCloud P, Hee J \& Burger H 1992 Age related changes in follicle stimulating hormone, luteinizing hormone, oestradiol and immunoreactive inhibin in women of reproductive age. Clinical Endocrinology 36 339-345.

Metcalf MG \& Livesey JH 1985 Gonadotrophin excretion in fertile women: effect of age and the onset of the menopausal transition. Journal of Endocrinology 105 357-362.

Metcalf MG, Donald RA \& Livesey JH 1981 Pituitary-ovarian function in normal women during the menopausal transition. Clinical Endocrinology 14 245-255.

Reame NE, Kelch RP, Beitins IZ, Mei-Yu Y, Zawacki CM \& Padmanabhan V 1996 Age effects on follicle-stimulating hormone and pulsatile luteinizing hormone secretion across the menstrual cycle of premenopausal women. Journal of Clinical Endocrinology and Metabolism 81 1512-1518.
Santoro N, Brown JR, Edel T \& Skurnick JH 1996 Characterization of reproductive hormonal dynamics in the perimenopause. Journal of Clinical Endocrinology and Metabolism 81 1495-1501.

Savage PJ, Rowlinson-Busza G, Verhoeyen M, Spooner RA, So A, Windust J, Davis PJ \& Epenetos AA 1993 Construction, characterisation and kinetics of a single chain antibody recognising the tumour associated antigen placental alkaline phosphatase. British Journal of Cancer 68 738-742.

Sherman BM, West JH \& Korenman SG 1976 The menopausal transition: analysis of $\mathrm{LH}, \mathrm{FSH}$, estradiol and progesterone concentrations during the menstrual cycles of older women. Journal of Clinical Endocrinology and Metabolism 47 629-636.

Sokoll LJ, Russel RM, Sadowski JA \& Morrow FD 1994 Establishment of creatinine clearance reference values for older wome. General Clinical Chemistry 40 2276-2281.

Yen SSC 1991 The human menstrual cycle. Neuroendocrine modulation. In Reproductive Endocrinology: Physiology, Pathology and Clinical Management, edn 3, pp 273-308. Eds SSC Yen \& RB Jaffe. Philadelphia: WB Saunders.

Zacur H, Kaufman SC, Smith B, Westhoff C, Helbig D, Lee YJ \& Gentile G 1997 Does creatinine adjustment of urinary pregnanediol glucuronide reduce or introduce measurement error? Gynecological Endocrinology 11 29-33.

Zumoff B, Strain GW, Miller LK \& Rosner W 1995 Twenty-four hour mean plasma testosterone concentration declines with age in normal premenopausal women. Journal of Clinical Endocrinology and Metabolism 80 1429-1430.

Received 7 August 2000

Accepted 7 March 2001 